\title{
Observación General 16 del Comité de Derechos Económicos, Sociales y Culturales: Mujeres e Igualdad
}

Cecilia Medina*

\section{Introducción}

El Comité de Derechos Económicos, Sociales y Culturales (Comité DESC o Comité) de las Naciones Unidas es un órgano establecido por resolución 1965/17del Consejo Económico y Social de esa Organización, de fecha 28 de mayo de 1985, para desempeñar las funciones de supervisión asignadas a ese Consejo en la parte IV del Pacto Internacional de Derechos Económicos, Sociales y Culturales (PIDESC). Esta resolución reparó la ausencia en el Pacto mismo de un órgano supervisor compuesto por expertos. La función del Comité es supervisar el cumplimiento de las obligaciones estatales que emergen del Pacto, lo que realiza principalmente mediante el examen de los informes que los Estados Partes deben presentarle periódicamente, lo que permite al Comité un análisis de la situación de todos los derechos humanos de manera simultánea y la elaboración de observaciones finales públicas. Para los efectos de ayudar a los Estados a presentar sus informes, y siguiendo la práctica del Comité de Derechos Humanos, el Comité DESC elabora observaciones generales, dirigidas a todos los Estados, que desarrollan los derechos del Pacto y las obligaciones de los Estados respecto de ellos. El Comité ha emitido ya 16 de estas observaciones, la última de las cuales, objeto de este comentario, explica el alcance y contenido del artículo 3 del PIDESC que dispone:

"Los Estados Partes en el presente Pacto se comprometen a asegurar a los hombres y a las mujeres igual título a gozar de todos los derechos económicos, sociales y culturales enunciados en el presente Pacto".

\section{La Observación General Nº16: Igualdad de derechos entre hombres y mujeres}

En la base del Derecho Internacional de los Derechos Humanos subyace un principio fundamental de la teoría de los derechos humanos: el principio de no discriminación. Si los derechos humanos son aquellos derechos inherentes al ser humano, todos los seres humanos deben poseerlos sin exclusiones. El principio de no discriminación está contemplado en todas las declaraciones y convenios generales sobre derechos humanos ${ }^{1}$. Este principio se aplica también a los derechos que están reconocidos en el derecho consuetudinario y a todas las áreas que se encuentren reguladas por el Estado. Sin embargo, su violación ha sido tan recurrente, que ha originado un sinnúmero de declaraciones y de convenios internacionales con el fin de enfatizar la prohibición de la discriminación por ciertos motivos ${ }^{2}$, o en ciertas áreas en las que estaba más intensamente amenazado o era violado de manera sistemática ${ }^{3}$.

* Codirectora del Centro de Derechos Humanos de la Facultad de Derecho de la Universidad de Chile, y Jueza de la Corte Interamericana de Derechos Humanos.

1 Ver Pacto Internacional de Derechos Civiles y Políticos, artículo 2.1; Declaración

Americana de los Derechos y Deberes del Hombre, artículo 2; Convención Americana de Derechos Humanos, artículo 1.1; Convenio para la Protección de los Derechos Humanos y de las Libertades Fundamentales, artículo 14, y Carta Africana sobre Derechos Humanos y de los Pueblos (Carta de Banjul), artículo 2.

2 Entre otros, pueden mencionarse los siguientes instrumentos: Declaración de las Naciones Unidas sobre la Eliminación de Todas las Formas de Discriminación Racial de 1963, Convención Internacional sobre la Eliminación de Todas las Formas de Discriminación Racial de 1965, Convención Internacional sobre la

Este comentario, junto con el documento principal a que se refiere, están disponibles en www.anuariocdh.uchile.cl 
Represión y el Castigo del Crimen de Apartheid de 1973; la Declaración sobre la Eliminación de Todas las Formas de Intolerancia y Discriminación Fundadas en la Religión o las Convenciones de 1981, Declaración sobre la Eliminación de la Discriminación contra la Mujer de 1967 y Convención sobre la Eliminación de Todas las Formas de Discriminación Contra la Mujer de 1979.

3 Entre otros, pueden mencionarse los siguientes instrumentos: Convenio sobre Igualdad de Remuneración de 1951, el Convenio sobre la

Discriminación (empleo y ocupación) de 1958 y la Convención relativa a la Lucha contra las Discriminaciones en la Esfera de la Enseñanza de 1960.

4 En adelante, todas las referencias a artículos se refieren a normas del PIDESC, a menos que se señale algo distinto.
EI PIDESC no escapa a esta lógica y el artículo 2.2. dispone que:

Los Estados Partes en el presente Pacto se comprometen a garantizar el ejercicio de los derechos que en él se enuncian, sin discriminación alguna por motivos de raza, color, sexo, idioma, religión, opinión política o de otra índole, origen nacional o social, posición económica, nacimiento o cualquier otra condición social.

No es raro, entonces, que la Observación General (Observación) comience con una explicación de por qué existe una disposición especial que, de alguna manera, se traslapa con la prohibición de discriminación establecida en el artículo 2.2 del PIDESC ${ }^{4}$, entre otras razones, sobre la base del sexo. El Comité DESC reconoce que, a pesar de la prohibición general, era necesario "reafirmar" en el Pacto la igualdad de derechos entre hombres y mujeres por los numerosos prejuicios existentes que impedían el cumplimiento pleno de las obligaciones de los Estados respecto de la igualdad en el goce de los derechos consagrados en el tratado, puesto que en la sociedad, tanto por tradición como por costumbre, se asignaba a las mujeres, y se les asigna hasta ahora, un estatus disminuido, el que produce aún una discriminación mayor cuando el hecho de ser mujer se cruza con otros factores como la raza o el color (párrafos 1 a 5 de la Observación).

La Observación comienza así elaborando el marco conceptual en que se basa el estudio del artículo 3, que contiene precisamente tres puntos que se refieren al tema: la igualdad, la no discriminación y las medidas especiales temporales.

En lo referente a la igualdad, se enfatiza el hecho de que la esencia del artículo 3 es el establecimiento de la obligación de asegurar a hombres y a mujeres una igualdad de hecho, no sólo de derecho. Esto significa que la ley y las políticas no sólo deben ser neutrales en términos de sexo, sino que deben asegurar que con ellas no se mantenga, sino que se disminuya "la desventaja inherente que experimentan" las mujeres, entre otros grupos. Los Estados deben respetar la igualdad en la ley, es decir, esta debe apuntar a promover iguales derechos económicos, sociales y culturales a hombres y mujeres, así como la igualdad ante la ley, lo que implica asegurar que las autoridades aplicarán la ley de manera igualitaria a hombres y mujeres (párrafos 6 a 9 de la Observación).

En cuanto a la no discriminación, la Observación repite la definición del término contenida en el artículo 1 de la Convención sobre la Eliminación de toda Forma de Discriminación contra la Mujer, donde se señala que es discriminatoria toda conducta que tenga por objeto o por resultado menoscabar o anular el reconocimiento, goce o ejercicio por la mujer de sus derechos humanos. Se aclara que esto significa que hay dos tipos de discriminación: la directa, cuando se diferencia claramente entre hombres y mujeres, sin justificación, y la indirecta, cuando una conducta que no quiere distinguir resulta por sus efectos en una distinción no justificada entre hombres y mujeres. De manera novedosa para un documento de este tipo, la Observación usa la palabra "género", 
explicando que ella se refiere a las expectativas culturales y presunciones acerca del comportamiento, actitudes, características personales y capacidades físicas e intelectuales de hombres y mujeres basadas solamente en el hecho del sexo (párrafos 10 a 14 de la Observación).

Finalmente, el Comité reafirma la legitimidad de las medidas especiales temporales que un Estado deba tomar para atenuar o suprimir las condiciones que perpetúan la discriminación de las mujeres, ya que constata que los principios de igualdad y no discriminación no son siempre suficientes para garantizar una verdadera igualdad (párrafo 15 de la Observación).

Una vez definido lo que la Observación Ilama "el marco conceptual", el Comité examina las obligaciones generales y específicas que se generan en el PIDESC. Comienza por reiterar lo que ya había dicho en su Observación General № 3 en el sentido de que el derecho del artículo 3 es de cumplimiento obligatorio e inmediato (párrafo 16), para sostener, a continuación, que existen tres niveles de obligaciones para los Estados Partes: respetar (respect), proteger (protect) y realizar (fulfil), agregando que esta última entraña tanto la obligación de proveer (provide) como la de promover (promote) y facilitar (facilitate) (párrafo 17). No es fácil trazar la línea divisoria en cada una de estas categorías y uno podría preguntarse si una distinción de esta especie es útil. El propio Comité no ha sido consecuente con las distinciones de los niveles, ya que en su Observación General № 12, sobre el Derecho a una Alimentación Adecuada, sostuvo que la obligación de realizar (fulfil) entrañaba solamente las ideas de facilitar (facilitate) y proveer (provide) y no menciona la de promover (promote $)^{5}$. En esa misma Observación, hay una nota al final del párrafo en que se aclara que:

Inicialmente se propusieron tres niveles de obligaciones: respetar, proteger y ayudar/realizar (véase El derecho a una alimentación adecuada como derecho humanos. Serie estudios $N^{0} 1$, Nueva York, 1989 (...) El nivel intermedio "facilitar" se ha propuesto como categoría del Comité, pero este ha decidido mantener los tres niveles de obligación).

En el presente texto se seguirá la distinción hecha por el Comité, pero es de advertir que los ejemplos que se dan para cada uno de los niveles de obligaciones no aclaran bien el criterio para identificar los ejemplos con uno u otro nivel.

La Observación no innova sobre el significado de la obligación de respetar, expresando que ella requiere que los Estados Partes no realicen conductas discriminatorias para el goce igualitario por hombres y mujeres de los derechos económicos, sociales y culturales. Esta obligación requiere que los Estados adopten o modifiquen leyes y pongan fin a políticas, programas o medidas administrativas incompatibles con el artículo 3, debiendo tomar en consideración para ello los posibles efectos discriminatorios de leyes, políticas o programas, aparentemente neutrales en términos de género (párrafo 18).
5 Observación General № 12, el Derecho a una Alimentación Adecuada (artículo 11), $20^{\circ}$ Período de Sesiones (1999), párr. 15. Lo mismo señala en la Observación General № 13, El Derecho a la Educación (Artículo 13), $21^{\circ}$ Período de Sesiones (1999), párr. 46. 
6 La palabra que se usa en la Observación es "remedies", que puede entenderse no sólo como "recursos", sino también como "reparaciones" en sentido lato.

7 El Comité de Derechos Humanos ha sido pionero en relacionar ambas categorías de derechos. Ver, por ejemplo, $\mathrm{CDH}$, Observación General $N^{\circ} 6$, Artículo 6 (16 ${ }^{\circ}$ período de sesiones), 30 de abril de 1982, párr. 5, donde el Comité incluye en la obligación de garantizar el derecho a la vida el preocuparse de la desnutrición infantil; $\mathrm{CDH}$, Observación General $N^{\circ} 25$, Artículo 25 (57음 período de sesiones), 12 de julio de 1996, párr. 12, donde el Comité señala entre las medidas que deben tomarse para garantizar el derecho a la participación política aquellas destinadas a combatir el analfabetismo, la pobreza y otros; y $\mathrm{CDH}$, Observaciones Finales del Comité de Derechos Humanos, Canadá (65ํํํodo de sesiones), 7 de abril de 1999, párr. 12, que contiene la necesidad de que Canadá se preocupe por la falta de vivienda de las personas que viven en la calle, como parte de su obligación de garantizar la vida. Ver también, en este Anuario, Abramovich, Víctor, Los estándares interamericanos de derechos humanos como marco para la formulación y el control de las políticas sociales.
La obligación de proteger no se diferencia en todos sus aspectos en esta Observación de la obligación de respetar, ya que requiere que los "Estados Partes tomen medidas dirigidas directamente a la eliminación de prejuicios y prácticas consuetudinarias u otras que perpetúen la noción de la inferioridad o superioridad de cualquiera de los sexos y los roles estereotipados para hombres y mujeres"; que se respeten y adopten normas constitucionales y legislativas sobre la igualdad de derechos de hombres y mujeres para gozar de todos los derechos humanos sin discriminación y normas legislativas para eliminar la discriminación tanto por el Estado como por terceros; que se adopten medidas y programas administrativos y se establezcan instituciones públicas, agencias y programas para proteger a las mujeres contra la discriminación (párrafo 19); y que se supervise y regule la conducta de agentes no estatales para que no se viole el artículo 3, como, por ejemplo, en el caso de servicios públicos que se han privatizado parcial o totalmente (párrafo 20).

La obligación de realizar exige que los Estados Partes "tomen medidas para asegurar que, en la práctica, hombres y mujeres gocen de sus derechos económicos, sociales y culturales sobre la base de la igualdad". La Observación da algunos ejemplos de este tipo de medidas, los que son de índole muy variada. El primer ejemplo, que recuerda las reparaciones que a menudo ordena la Corte Interamericana de Derechos Humanos, incluye desde hacer accesibles y disponibles los recursos ${ }^{6}$ apropiados, tales como compensación, reparación, restitución, rehabilitación, garantías de no repetición, declaraciones, disculpas públicas, hasta la realización de programas educacionales y de prevención. Otros ejemplos se refieren al diseño e implementación de políticas y programas para dar efecto duradero a la igualdad de goce de estos derechos a hombres y mujeres, incluyendo medidas temporales especiales, como la asignación directa de recursos financieros para estos efectos; el establecimiento de recursos judiciales accesibles a las personas más pobres y en situación de más desventaja; el diseño y desarrollo de programas de educación y entrenamiento a jueces y agentes estatales; la integración del principio de igualdad en los colegios y otros programas educacionales, y la promoción de la igualdad de participación en los planes de desarrollo, para la toma de decisiones y para los beneficios del desarrollo. En resumen, indica medidas para asegurar el cumplimiento del artículo 3 en todos estos campos.

La Observación también destina una sección a dar ejemplos del contenido de las obligaciones de ciertos derechos específicos, para mostrar el efecto transversal que el artículo 3 tiene en el PIDESC. Esta es, sin dudas, la sección más interesante y lo hubiera sido aun más si el Comité no mostrara a veces una inclinación a hablar de las obligaciones para todos, en vez de centrarse en aquello que el Estado no hace precisamente respecto de los derechos de las mujeres para así ayudar a conseguir la igualdad de goce de hombres y mujeres de los derechos económicos, sociales y culturales. Algo que merece la pena relevar es cómo se advierte de los ejemplos la íntima relación entre los derechos civiles y políticos y los económicos, sociales y culturales ${ }^{7}$. 
Se destaca también que se incluya como obligación del Estado, derivada del artículo 7, identificar y, consecuentemente, eliminar las causas que subyacen a las diferencias de sueldos y salarios entre hombres y mujeres y reducir los obstáculos para conciliar las responsabilidades profesionales y familiares. Se echa de menos, por ejemplo, que la Observación no diga que, al controlar el cumplimiento por el sector privado de la legislación laboral (lo que señala como una obligación a favor de hombres y mujeres), no mencione la situación de las mujeres en el servicio doméstico, en el trabajo temporal en el campo u otras semejantes, en cuanto a su absoluta o parcial falta de vinculación con normas legales que las protejan (párrafo 24).

También destacable es que se mencione, como obligación emergente del artículo 9, la obligación de igualar para hombres y mujeres la edad de retiro obligatorio ${ }^{8}$, asegurar igual beneficio de los sistemas de pensión públicos y privados ${ }^{9}$ y garantizar el permiso maternal, paternal y parental (párrafo 26).

La confluencia de aspectos económicos, sociales y culturales con los civiles y políticos se advierte claramente en los párrafos 27 y 28 dedicados a los artículos 10 y 11 del PIDESC, que son, por lo demás, interesantes en cuanto a la perspectiva de género. El artículo 10, que ordena dar la más amplia protección y asistencia posibles a la familia, incorpora ya aspectos civiles, puesto que dispone en el número 1 que "[e]l matrimonio debe contraerse con el libre consentimiento de los futuros cónyuges", lo que es similar al artículo 23.3 del Pacto Internacional de Derechos Civiles y Políticos, que establece que [el] matrimonio no podrá celebrarse sin el libre y pleno consentimiento de los futuros cónyuges". Desarrollando el artículo 1, la Observación expresa de manera similar a la Observación General № 28 del Comité de Derechos Humanos, la idea de que la edad legal para contraer matrimonio debe ser igual para hombres y mujeres ${ }^{10}$; pero, además, incorpora entre las obligaciones que se generan con esta disposición la necesidad de que los Estados provean a las víctimas de violencia doméstica un refugio seguro, recursos y reparaciones por el daño que hayan sufrido y de que aseguren que existan para las mujeres iguales derechos a la propiedad matrimonial y a la herencia en caso de muerte del cónyuge.

En el caso del artículo 11, que reconoce el derecho de toda persona a un nivel de vida adecuado para sí y su familia, la Observación requiere que las mujeres tengan el derecho al dominio, uso y control de su vivienda, tierra u otra propiedad, así como acceso y control de los medios de producción de alimentos. También se hace cargo el Comité de la realidad al interpretar el artículo 11 en el sentido de que obliga al Estado a enfrentar las prácticas consuetudinarias que no permiten que una mujer se alimente hasta tanto todos los hombres han sido plenamente alimentados o que conceden a la mujer la posibilidad de comer sólo alimentos menos nutritivos (párrafo 28).

La interpretación de las obligaciones derivadas del artículo 12 del PIDESC, que reconoce el derecho de toda persona al disfrute del más alto nivel
8 En Chile se debate hoy no la igualdad de edad en el retiro obligatorio, sino en el derecho a jubilar y, de acuerdo a lo que se informa en la prensa, parecería haber una posición opuesta a la del Comité en esta Observación № 16.

9 Las desigualdades en este campo siguen subsistiendo en Chile. Los artículos 6 y 7 del DL 3500 de 1980, que distinguen entre hombres y mujeres en cuanto generadores de pensiones de supervivencia. A diferencia del hombre, la mujer que ha hecho sus aportes sociales mientras trabajaba no es causante de pensión para el viudo, a menos que éste sea inválido.

10 El Comité de Derechos Humanos expresa esto diciendo que la edad mínima para contraer matrimonio "debería ser fijada por el Estado sobre la base de la igualdad de criterios para el hombre y la mujer". Observación General № 28, Artículo 3 - La igualdad de derechos entre hombres $y$ mujeres, $68^{\circ}$ Período de Sesiones (2000), párr. 23. 
posible de salud física y mental, es particularmente interesante, porque relaciona la salud con el efecto de los roles de género en el acceso a agua y a alimentos, ambos determinantes para la salud; con las restricciones legales en las normas que regulan la salud reproductiva; con la existencia de la mutilación genital femenina, y con la posible falta de entrenamiento adecuado para los trabajadores de la salud que se ocupan de los problemas de salud de las mujeres (párrafo 29).

En las obligaciones del artículo 13, que reconoce a todos el derecho a la educación, la perspectiva de género se refleja en la obligación de los Estados de hacer desistir a las familias de dar tratamiento preferencial a los niños para asistir a la escuela, lo que se debe hacer particularmente a través de campañas de información y de concientización (párrafo 30).

En la sección III, la Observación se ocupa de la implementación del Pacto en el ámbito nacional y comienza expresando que "[t]odo Estado Parte tiene un margen de discreción en la adopción de medidas para cumplir con sus obligación inmediata y principal de asegurar a hombres y mujeres igual título para el goce de sus derechos económicos, sociales y culturales". Es de esperar que esto se entienda en el sentido de que la discreción de los Estados no se refiere a la determinación de si adopta o no medidas, sino que sólo a la elección de las mismas con el fin de que sean las más apropiadas para cumplir con sus obligaciones internacionales. El énfasis de la sección está puesto en la necesidad de adoptar medidas temporales especiales para alcanzar la igualdad sustantiva entre hombres y mujeres (párrafos 32 a 37), de establecer mecanismos e instituciones efectivas para investigar las posibles violaciones al artículo 3 y proveer las reparaciones adecuadas (párrafo 38), y de identificar indicadores y metas de referencia (benchmarks) para poder supervisar el cumplimiento del artículo 3. Para lo último, se señala que puede ser apropiado disponer de estadísticas desagregadas por sexo (párrafo 39).

Finalmente, la última sección de la Observación, titulada "Violaciones", está destinada a poner de relieve nuevamente que el artículo 3 debe entenderse violado cuando el Estado no ha cumplido con las obligaciones mencionadas previamente, ya sea a través de una acción o una omisión, e incluso cuando ha adoptado medidas regresivas en el igual goce entre hombres y mujeres de los derechos contenidos en el PIDESC (párrafos 40 a 42), puesto que esta norma establece una obligación primaria y de cumplimiento inmediato. 